\title{
Diagnostic and prognostic value of the new tumour marker CYFRA 21-1 in patients with squamous cell lung cancer
}

\author{
J. Niklinski*, M. Furman*, E. Chyczewska**, \\ L. Chyczewski+, F. Rogowski++, J. Laudanski*
}

\begin{abstract}
Diagnostic and prognostic value of the new tumour marker CYFRA 21-1 in patients with squamous cell lung cancer. J. Niklinski, M. Furman, E. Chyczewska, L. Chyczewski, F. Rogowski, J. Laudanski. @ ERS Journals Ltd 1995.

ABSTRACT: We wanted to investigate the diagnostic and prognostic significance of serum CYFRA 21-1, especially in predicting the risk of recurrence in patients with operable squamous cell lung cancer.

Serum levels of CYFRA 21-1 were measured using an immunoradiometric assay (CIS bio) in 76 patients with squamous cell lung cancer (64 operable and 12 with unresectable tumours), 22 with other non-small-cell type (12 with adenocarcinoma and 10 with large-cell type) and 45 with nonmalignant lung diseases.

Elevated preoperative CYFRA $21-1$ levels were identified in $63 \%$ of patients with squamous cell type (SqCC), 33\% with adenocarcinoma, and $30 \%$ with large-cell carcinoma type. The diagnostic specificity of the assay was $96 \%$. Positive CYFRA 21-1 levels were observed in $33 \%$ of stage I, $52 \%$ of stage II, $76 \%$ of stage IIIa and $83 \%$ of stage IIIb patients with SqCC type. Statistically significant differences were obtained between stages I and II and between II and IIIa, but not between stages IIIa and IIIb. Recurrence-free survival probability for patients with elevated serum CYFRA 21-1 levels before surgery was $63 \%(24 / 38)$ versus $92 \%(24 / 26)$ for patients with normal serum CYFRA 21-1 levels. However, the difference was not statistically significant when adjusted for the TNM stage (primary tumour, regional lymph node involvement, occurrence of distant metastasis). In 9 of the 10 patients with increased trend for CYFRA 21-1 during follow-up, elevated serum CYFRA 21-1 levels preceded (7) or coincided (2) with the clinical detection of tumour recurrence, providing a predictive value of an increased trend of $90 \%$. In the multivariate analysis, the association of the increase of CYFRA 21-1 level with a higher risk of recurrence was statistically significant.

Our results indicate that CYFRA 21-1 may be a useful marker in SqCC. Serial determination of CYFRA 21-1 was consistent with the treatment results and the serum CYFRA 21-1 levels were shown to reflect the disease process during followup. Rising serum CYFRA 21-1 levels in patients after tumour resection were an early indicator of tumour recurrence.

Eur Respir J., 1995, 8, 291-294.
\end{abstract}

\author{
Depts of *Thoracic Surgery, **Pneumono- \\ logy, +Pathology and ++Nuclear Medicine, \\ Medical School, Bialystok, Poland. \\ Correspondence: J. Niklinski \\ Dept of Thoracic Surgery \\ Medical School \\ 24a M.Sklodowska-Curie Str. \\ 15-276 Bialystok \\ Poland \\ Keywords: CYFRA 21-1 \\ lung cancer \\ tumour marker
}

Received: February 91994

Accepted after revision November 191994
Lung tumour markers can be classified into several categories including peptide and nonpeptide hormones, oncofoetal proteins, enzymes, structural proteins and membrane antigens. The expression of biochemical markers by lung tumours has been known for many years, but the role of biomarkers in the diagnosis and prognosis of lung cancer is still unclear. Clinical use of carcinoembryonic antigen, tissue polypeptide antigen and squamous cell carcinoma antigen is widespread [14].

However, in recent years a number of interesting developments have occurred, especially in the field of markers which represent certain degradation products. Cytokeratins are proteins of the intermediate filament family, main components of the cell cytoskeleton. The cytokeratin family is expressed by all epithelial cells and appears to be a useful marker of epithelial differen- tiation [5-8]. Cytokeratin 19 has a low molecular weight of $40 \mathrm{kDa}$. It is expressed and immunohistochemically detectable in the cytoplasm of epithelial tumour cells, including bronchial cancers [5, 6]. Although cytokeratins are part of the cytoskeleton, some fragments might be released in the serum owing to cell lysis or tumour necrosis. For these reasons, the cytokeratin subunit 19 fragment can be treated as a tumour marker for lung cancer. A fragment of cytokeratin subunit 19 can be measured in serum by a new immunoradiometric assay, the CYFRA 21-1 using two mouse monoclonal antibodies (MoAbs) KS 19-1 and BM 19-21. This cytokeratin 19 fragment is referred to as CYFRA 21-1.

The aim of this study was to examine the diagnostic and prognostic significance of serum CYFRA 21-1, especially in predicting the risk of recurrence in patients with operable squamous cell lung cancer. 


\section{Subjects and methods}

The study includes 98 non-small-cell lung cancer (NSCLC) patients and 45 with nonmalignant lung diseases (tuberculoma, hamartoma, lung fibrosis, pulmonary emphysema) examined by the Chest Oncology Group and operated in the Thoracic Surgery Unit at the Bialystok Medical School between January 1991 and May 1992. Among patients with NSCLC, 76 had squamous cell carcinoma (SqCC), 12 had adenocarcinoma (AC) and 10 had large-cell carcinoma (LCC). Of these patients, 84 underwent surgical resection (64 with SqCC, 10 with AC, and 10 with LCC), four had an exploratory thoracotomy (three with SqCC and one with $\mathrm{AC}$ ) and 10 did not undergo operation (nine with $\mathrm{SqCC}$ and one with $\mathrm{AC}$ ). Routine pretreatment staging procedures included physical and blood examinations, chest radiographs and tomograms, bronchoscopy, computerized tomography (CT) of the thorax and brain, and ultrasound scanning of liver. In addition, radioisotopic scans of bones, examination of bone marrow aspirates, and abdominal CT scan were performed when necessary. Selected patients underwent mediastinoscopy. During operation, radical lymph node dissection was uniformly performed. Nodes were identified and submitted separately at all levels. Pathological material has been specially reviewed for this study by the same pathologist. Postoperative, pathological staging (pTNM) (primary tumour, regional lymph node involvement, occurrence of distant metastasis) was performed by correlating the operative and histological findings [9]. After surgery, patients were followed-up to evaluate the recurrence rate. Clinical and radiological examinations were repeated bimonthly. The median follow-up was 24 months (range 6-34 months).

Tumour recurrence was detected in 16 patients $(25 \%)$ among those operated on with stages I, II and IIIa (64 patients). Recurrence was local in four patients and distant in 12 patients. The anatomical distribution of the distant recurrences was: contralateral lung in three patients; bones in four patients; brain in two patients; and multiple sites in three patients. Two of four patients with local recurrence were able to undergo a second resection, and both are alive without evidence of disease at 1 and $1.5 \mathrm{yrs}$ after the second operation. The other two patients could not undergo resection because of insufficient pulmonary reserve. Both were treated with radiation therapy and died from disease progression. Chemotherapy was offered to any patient with good performance status and disseminated disease.

To determine CYFRA 21-1 serum levels, venous blood samples were collected from each patient before surgery, on days 14 and 30 postsurgery, and subsequently every 2 months for 2 yrs. Serum samples were obtained by centrifugation and stored at $-80^{\circ} \mathrm{C}$ until assayed. All samples were assayed in duplicate. Serum levels of CYFRA 21-1 were measured with immunoradiometric assay, using a commercial source (CIS bio international, Gif/Yvette, France), following the manufacturer's instructions. The cut-off point was $3.6 \mathrm{ng} \cdot \mathrm{ml}^{-1}$.

Data were reported as median and statistically analysed with Wilcoxon's test. Univariate survival analyses were based on the Kaplan-Meier product-limit estimates of the survival distribution. Differences between survival curves were tested statistically using Mantel's logrank test or its stratified version. The relative importance of prognostic factors on recurrence-free survival was estimated using Cox's proportional hazard model with time-dependent covariates [10]. A p-value of less than 0.05 was regarded as statistically significant.

\section{Results}

At the time of diagnosis, 56\% (55/98) of all NSCLC patients (SqCC + AC + LCC), and 4\% (2/45) with nonmalignant lung diseases had CYFRA 21-1 levels higher than $3.6 \mathrm{ng} \cdot \mathrm{ml}^{-1}$. The highest median of CYFRA 21-1 was found in patients with SqCC (table 1), and there were 48/76 (63\%) patients with CYFRA 21-1 levels above 3.6 $\mathrm{ng} \cdot \mathrm{ml}^{-1}$. The median value of $5.1 \mathrm{ng} \cdot \mathrm{ml}^{-1}$ was significantly higher than in other histological types: adenocarcinoma $(\mathrm{p}<0.001)$ and large-cell carcinoma $(\mathrm{p}<0.001)$.

Table 1 refers to the CYFRA 21-1 assays, according to the stage of SqCC group. Both median levels of CYFRA 21-1 and the marker sensitivity were more elevated in advanced stages. However, statistically significant differences were obtained between stages I and II $(\mathrm{p}<0.01)$, and between II and IIIa $(\mathrm{p}<0.001)$, but not between stages IIIa and IIIb $(\mathrm{p}>0.05)$.

After 24 months of monitoring, recurrence was observed in 16/64 SqCC patients (25\%). Recurrence-free survival probability curves, according to different pretreatment serum CYFRA 21-1 levels, are presented in figure 1 . Based on the survival curves, the 2 yr recurrence-free survival rate for patients with an elevated serum CYFRA 21-1 level before surgery was 63 versus $92 \%$ for those with a normal level. When compared by means of the log-rank test, the curves differ significantly at the 0.05 significance level $(p=0.02)$; but when they are compared using the stratified log-rank test, with strata defined by the TNM stages, the difference is not significant $(\mathrm{p}=0.3)$.

Table 1. - Relationship of CYFRA 21-1 to the histological type of NSCLC and the stage of disease in SqCC type in 98 patients

\begin{tabular}{lccc}
\hline & $\begin{array}{c}\text { Patients } \\
\mathrm{n}\end{array}$ & $\begin{array}{c}\text { Sensitivity } \\
\%\end{array}$ & $\begin{array}{c}\text { CYFRA 21-1* } \\
\mathrm{ng} \cdot \mathrm{ml}^{-1}\end{array}$ \\
\hline SqCC & 76 & 63 & $5.1(0.5-30.5)$ \\
Stage I & 12 & 33 & $1.1(0.5-4.8)$ \\
Stage II & 23 & 52 & $3.7(1.4-10.9)$ \\
Stage IIIa & 29 & 76 & $6.8(1.1-30.5)$ \\
Stage IIIb & 12 & 83 & $7.4(1.9-19.4)$ \\
AC & 12 & 33 & $2.1(0.6-4.5)$ \\
LCC & 10 & 30 & $2.4(1.0-4.9)$ \\
\hline All patients & 98 & 56 & $5.1(0.5-30.5)$ \\
\hline *: data are presented as median, and range in parenthesis. \\
NSCLC: non-small-cell lung cancer; SqCC: squamous cell \\
carcinoma; AC: adenocarcinoma; LCC: large cell carcino- \\
ma.
\end{tabular}




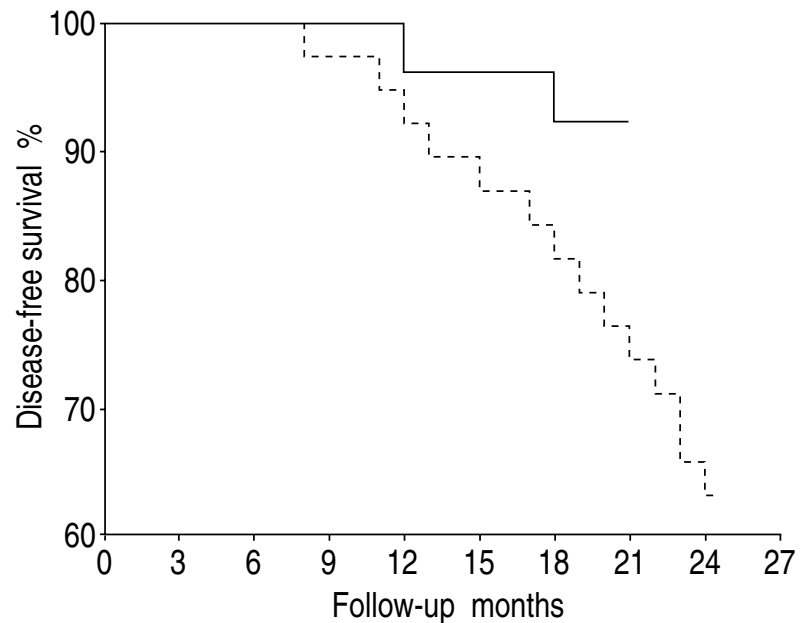

Fig. 1. - Relapse-free survival probability (\%) of 64 SqCC patients according to different pretreatment serum CYFRA 21-1 values. - $\quad$ s-CYFRA $21-1<3.6 \mathrm{ng} \cdot \mathrm{ml}^{-1}$ (26 patients); - - - -: s-CYFRA 21-1: $>3.6 \mathrm{ng} \cdot \mathrm{ml}^{-1}$ (38 patients). SqCC: squamous cell carcinoma.

In 9 of the 10 patients with increased trend for CYFRA 21-1 during follow-up, elevated serum CYFRA 21-1 levels preceded ( 7 patients; median $8.2 \mathrm{ng} \cdot \mathrm{ml}^{-1}$ ) or coincided ( 2 patients; median $6.9 \mathrm{ng} \cdot \mathrm{ml}^{-1}$ ) with the clinical detection of tumour recurrence, providing a predictive value of an increased trend of $90 \%$. In the group of 7 patients who showed elevated serum CYFRA 21-1 level prior to the detection of recurrence, the median lead-time (from detection of elevated CYFRA 21-1 to detection of recurrence) was 3.1 months (range 2-6 months).

To investigate the effect of the change of CYFRA 211 level in time on recurrence-free survival adjusting for the TNM stage, a multivariate analysis was performed. The analysis was based on the proportional hazard model. A binary covariate for TNM stage $(=1$ for stage IIIa, and $=0$ for stage I and II) and a time-dependent binary covariate for the CYFRA 21-1 level change (=1 for an elevated level, and $=0$ for a normal level) were included in the model. While tested at 0.05 significance level using the score test, both covariates appeared to be statistically significant in the model $(\mathrm{p}=0.03$ for TNM stage and $\mathrm{p}<0.00005$ for the change of CYFRA 21-1 level) indicating an association of TNM stage IIIa and of the change of CYFRA 21-1 from a normal to an

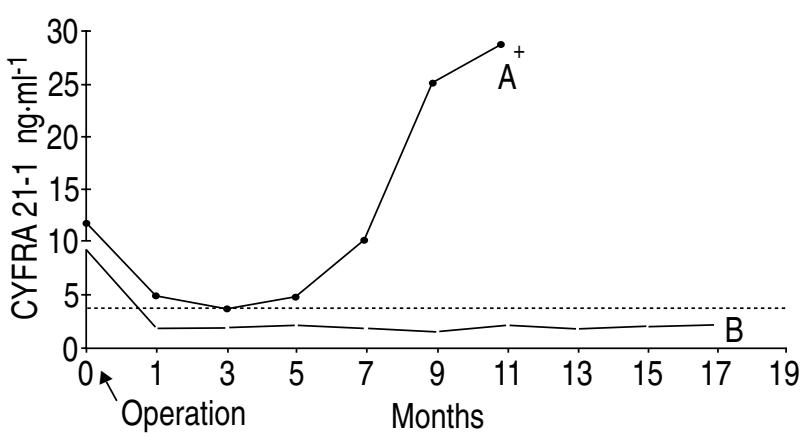

Fig. 2. - Serum CYFRA 21-1 levels in two typical SqCC patients with different courses after tumour resection. Patient A (+) died of bone metastasis; patient B is alive and well. …..: $3.6 \mathrm{ng} \cdot \mathrm{ml}^{-1}$ cut off level. elevated level with a higher risk of recurrence. Figure 2 shows the sequence of changes in serum CYFRA 211 levels in two typical patients (both with pTNM IIIa) with different postoperative courses.

\section{Discussion}

The results of initial studies of CYFRA 21-1 were published in 1992 and showed its significant value in nonsmall-cell lung cancer [11]. This study demonstrates that the serum assay CYFRA 21-1 was significantly higher for the squamous cell carcinoma type than for all other histological types, in accordance with observations by others [12]. Generally, increased marker levels were correlated with progression of SqCC tumour stage, with one exception - we found no difference between stage IIIa and stage IIIb. In our previous study [13], we observed a significant relationship between the level of CYFRA 21-1 and mediastinal lymph node involvement, but we found no correlation between stages N0 and N1. Similar data were obtained by other investigators [14], who also suggested that CYFRA 21-1 might be considered as a marker of tumour mass. In addition, they pointed out that it is impossible to predict operability of NSCLC using the serum level of this marker. Those authors also noticed the prognostic values of pretreatment levels of CYFRA 21-1.

Our previous study [13] showed that patients with pretreatment elevated CYFRA 21-1 levels had shorter survival time, but the tendency did not reach statistical significance. In this study, we obtained a relationship between CYFRA 21-1 and prognosis. Two year recurrence-free survival rate for patients who had abnormal serum CYFRA 21-1 level was 63 versus 92\% when a normal serum CYFRA 21-1 level was found. However, the difference in recurrence-free survival between those two groups of patients was not statistically significant when adjusted for the TNM stage.

Our follow-up data, nevertheless, indicate that serial determinations of CYFRA 21-1 are of prognostic value after surgical treatment of patients with SqCC. In 9 of the 10 patients with increased trend, recurrence was observed. In $89 \%$ (48 of 54) of patients with normal CYFRA 21-1, no recurrence was observed. In the multivariate analysis (taking into account the TNM stage) the association of the increase of CYFRA 21-1 level with a higher risk of recurrence was found to be statistically significant. These observations are consistent with preliminary data of EBERT et al. [15] and DIENEMANN et al. [16]. They also found that CYFRA 21-1 is able to predict both success and failure of therapy as well as relapse, prior to clinical signs. Additionally, VAN DER GAAST et al. [17] suggested a value of CYFRA 21-1 especially for disease monitoring of patients with SqCC during and after chemotherapy.

We conclude that CYFRA 21-1 may be a useful marker in SqCC. Serial determination of the CYFRA 21-1 was consistent with the treatment results, and the serum CYFRA 21-1 levels were shown to reflect the disease process during follow-up. 
Acknowledgements: Donation of CYFRA 21-1 kits by CIS bio (Gif-sur-Yvette, France) is gratefully acknowledged. Special thanks are due to A. Kostrzewska and T. Burzykowski for statistical analyses.

\section{References}

1. Buccheri GF, Ferrigno D, Sartoris AM, Violante B, Vola $\mathrm{F}$, Curcio A. Tumor markers in bronchogenic carcinoma: superiority of tissue polypeptide antigen to carcinoembryonic antigen and carbohydrate antigenic determinant 19-9. Cancer 1987; 60: 42-50.

2. Buccheri GF, Violante B, Sartoris AM, Ferrigro D, Curcio A, Vola F. Clinical value of a multiple biomarker assay in patients with bronchogenic carcinoma. Cancer 1986; 57: 2389-2396.

3. Niklinski J, Furman M, Laudanski J, Kozlowski M. Prognostic value of pretreatment CEA, SCC-Ag and CA19-9 levels in sera of patients with non-small-cell lung cancer. Eur J Cancer Prev 1992; 1: 401-406.

4. Ebert W, Kayser K, Buelzebruck H, Vogt-Moykopf I. Diagnostic validity of the SCC antigen assay in squamous cell carcinoma of the lung. J Tumor Markers Oncol 1988; 3: 35-44.

5. Moll R, Franke WW, Schiller DL, Geiber B, Krepler R. The catalogue of human cytokeratins: patterns of expression in normal epithelia, tumors and cultured cells. Cell 1982; 31: 11-24.

6. Broers JLV, Ramaekers FCS, Rot MK, et al. Cytokeratins in different types of human lung cancer as monitored by chain-specific monoclonal antibodies. Cancer Res 1988; 48: 3221-3229.

7. Debus E, Moll R, Franke WW, Weber K, Osborn M. Immunohistochemical distinction of human carcinomas by cytokeratin typing with monoclonal antibodies. $\mathrm{Am}$ J Pathol 1984; 114: 121-130.
8. Osborn M, Weber K. Intermediate filaments: cell-typespecific markers in differentiation and pathology. Cell 1982; 31: 303-306.

9. Mountain CF. A new international staging system for lung cancer. Chest 1986; 89 (Suppl.): 225-233.

10. Cox DR. Regression models and life tables (with discussion). J R Stat Soc (Series B) 1972; 34: 187-220.

11. Hasholzner U, Stieber P, Fiebig M, Sunder-Plassmann L, Fateh-Maghadam A. CYFRA - a new tumor marker for non-small-cell lung cancer (NSCLC). In: Klapdor $\mathrm{R}$, ed. Tumor associated antigens, oncogens, receptors, cytokines in tumor diagnosis and therapy at the begining of the nineties. Cancer of the breast: state and trends in diagnosis and therapy. Muchen-Bern-New York, W. Zuckschwerdt Verlag, 1992, pp. 134-136.

12. Stieber P, Hasholzner U, Bodenmuller H, et al. CYFRA 21-1: a new marker in lung cancer. Cancer 1993; 72: 707-713.

13. Niklinski J, Furman M, Chyczewska E, et al. Evaluation of CYFRA 21-1 as a new marker for non-small-cell lung cancer. Eur J Cancer Prev 1994; 3: 227-230.

14. Pujol JL, Grenier J, Daures JP, Daver A, Pujol H, Michel FB. Serum fragment of cytokeratin subunit 19 measured by CYFRA 21-1 immunoradiometric assay as a marker of lung cancer. Cancer Res 1993; 53: 61-66.

15. Ebert W, Leichtweis B, Schapohler B, Muley Th. The new tumor marker CYFRA 21-1 is superior to SCC antigen and CEA in the primary diagnosis of lung cancer. Tumor Diagn Therap 1993; 3: 91-99.

16. Dienemann H, Stieber P, Zimmermann A, Hoffmann H, Muller C, Banauch D. Tumor-marker CYFRA 21-1 in non-small-cell lung cancer (NSCLC): role for detection of recurrence. Lung Cancer 1994; 11 (Suppl. 1): 46.

17. van der Gaast A, Schoenmakers CHH, Kok TC, Blijenberg BG, Cornillie F, Splinter TAW. Evaluation of a new tumour marker in patients with non-small-cell lung cancer: CYFRA 21-1. Br J Cancer 1994; 69: $525-528$. 